\title{
Canada and US going opposite directions on conscientious objection for doctors
}

\author{
— Cite as: CMAJ 2018 March 5;190:E270-1. doi: 10.1503/cmaj.109-5572
}

Posted on cmajnews.com on Feb. 12, 2018.

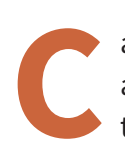
anadian faith-based doctor groups are arguing that their conscientious objection rights were dealt a major blow following an Ontario court decision. South of the border, meanwhile, medical associations, providers and ethicists are concerned about sweeping proposed regulations aimed at protecting doctors' rights to conscientious objection.

The US Health and Human Services Department (HHS) recently announced the creation of a new "Conscience and Religious Freedom Division" to investigate health providers' complaints that their rights have been violated. In addition, the department announced proposed regulation changes that would increase powers of enforcement, and allow it to interpret existing laws regarding conscientious objection more broadly.

A Canadian court moved in the opposite direction. On Jan. 31, the Ontario Divisional Court ruled that the College of Physicians and Surgeons of Ontario's (CPSO) "effective referral" requirement was a reasonable limit on the religious freedoms of doctors, necessary to prevent harm and inequitable access for patients. Effective referral requires doctors or their designates to call another provider or service, such as the province's care coordination service phone line, to connect patients with doctors or nurse practitioners who provide medical assistance in dying.

Larry Worthen, executive director of the Christian Medical and Dental Society, said his group wants doctors to be able to provide patients with the care coordination phone number so they can call themselves. For hospital-based patients who cannot make phone calls, care could be transferred to another provider in the hospital to facilitate referrals, said Worthen.
"Our concern is when you're actually the one to be forced to connect the patient with the provider, you're actually assisting the patient in accessing the service," said Worthen. "If [assisted dying] were still illegal, if you did that much you would be participating in a criminal act."

Noting that federal law doesn't require doctors to assess patients for, or conduct, assisted dying, Kathryn Clarke, senior communications advisor at the CPSO, stated that "the CPSO does not consider providing the patient with an effective referral as assisting in providing medical assistance in dying." She added that the effective referral requirement ensures all physicians "uphold their pro-

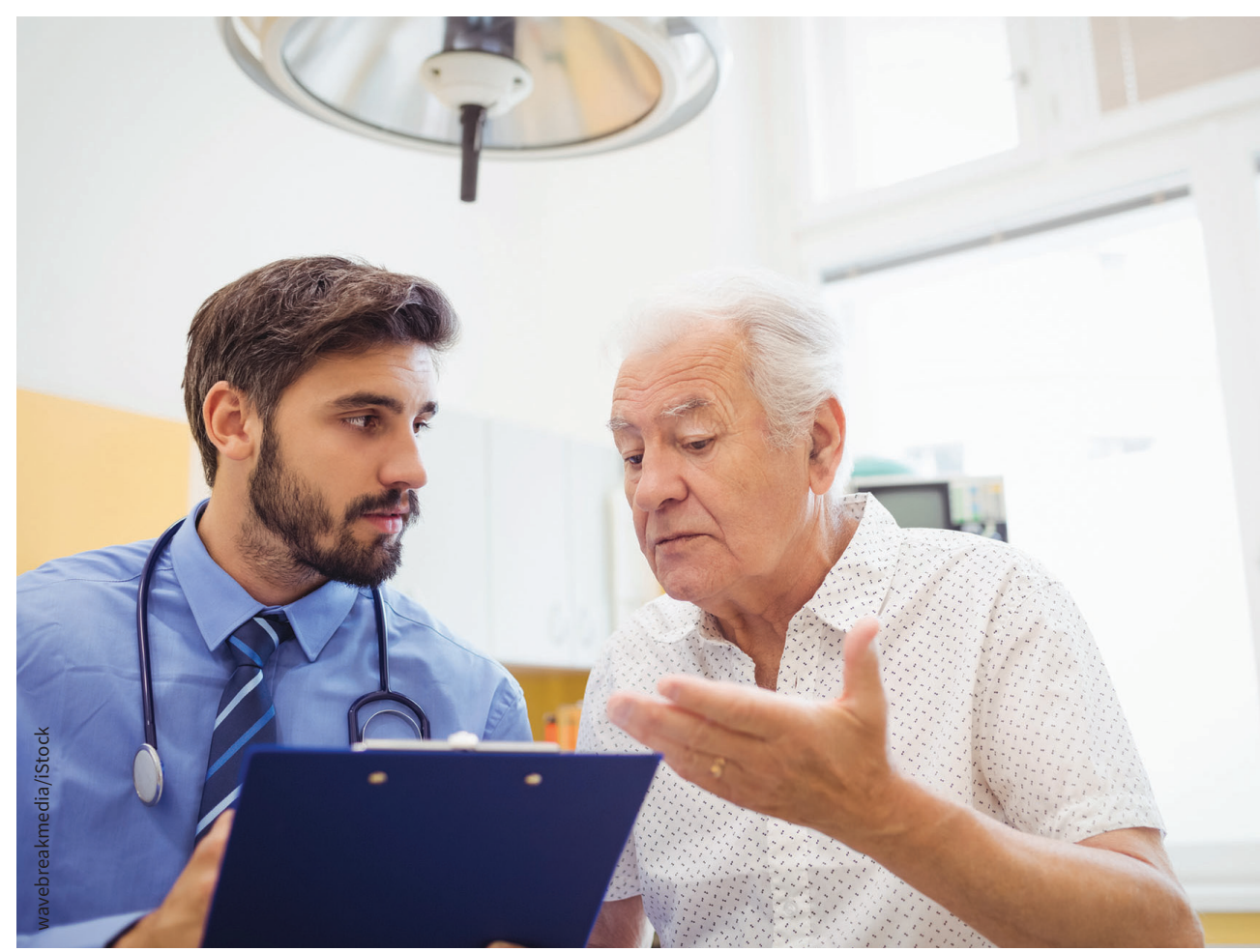

Some physicians object to referring patients directly for services they believe violate their conscience. fessional and ethical obligations of nonabandonment" and "that the most vulnerable are not exposed to harm when their physician objects to providing an otherwise appropriate and available medical service."

In the US, meanwhile, the HHS is proposing to broaden physicians' rights to refuse to assist in referrals or services they consider objectionable. The proposed rules would expand their rights to refuse to refer for abortion, for example. Critics have expressed concern that they will also limit access to birth control, medical services for transgender people, and more.

"I'm concerned for the person who is a rape victim, the woman who requires 
emergency care because of an ectopic pregnancy, and that it's now going to be permissible for a nurse who is a Jehovah's Witness to say, "I don't want to hang blood in an emergency setting," said Dr. Lainie Friedman Ross, a physician and professor of clinical medical ethics at the University of Chicago.

An email statement from the American Medical Association (AMA) said it is still assessing the 52-page legal document that proposes changes to allow the HHS to interpret and enforce existing laws pertaining to conscientious objection more broadly. "[The AMA is] assessing the breadth of the proposed regulation, which appears to encompass and intertwine many separate laws and may, in fact, inappropriately expand the reach of some."

While it is still unclear how the proposed HHS division would rule on actual complaints, a stronger stance on conscientious objection is likely to increase official complaints of violations against conscience and religion. Since the HHS's Office of Civil Rights was given authority to enforce federal health care conscience laws in 2008, it has received 44 complaints -34 of them filed since Donald Trump was elected president.

Ross said the proposed new division is a political move, rather than a response to actual rights infringements. "The law is very problematic because it forgets that doctors are powerful individuals and patients are vulnerable. This law is all about protecting doctors, not the individuals who need the protection - those who are sick and frightened."

Wendy Glauser, Toronto, Ont. 